\title{
Blended support of undergraduate interdisciplinary research
}

\section{Rianne van Lambalgen}

Institute for Cultural Inquiry, Utrecht University, The Netherlands.

\begin{abstract}
This paper discusses blended support for undergraduate students to perform interdisciplinary research in teams. Interdisciplinary research is a complex process that consists of multiple steps and requires collaboration with people from different backgrounds. This paper presents research done at Liberal Arts and Sciences, Utrecht University (LAS), where students learn to do interdisciplinary research as part of the core curriculum. Considering the complexity of doing interdisciplinary research, it is important that students are guided in this process. Blended support that combines technologymediated guidance and face-to-face meetings would be of use to help students become more independent interdisciplinary researchers. This paper explores preferences in blended support, based on a survey and interviews with second and third year students and with undergraduate research supervisors at LAS, UU. Results indicated that there are different activities during the interdisciplinary research process where technology-mediated support would be of value. However, students and supervisors especially value meeting face-to-face when doing interdisciplinary integration. This should be taken into account when designing a blended framework for support of undergraduate interdisciplinary research.
\end{abstract}

Keywords: Interdisciplinary education; undergraduate research; blended learning; educational technology. 


\section{Introduction}

Nowadays, technology provides the means to create online or blended educational environments, with different benefits for student learning such as facilitating a student's self-regulation (Shea \& Bidjerano, 2010) and supporting a student's deep learning (Garrison \& Kanuka, 2004). This paper discusses the value of using blended learning for support of students doing undergraduate interdisciplinary research. What is typical of undergraduate research is that students do not have much experience with doing research and support often focuses on providing structure. (Todd et.al., 2004). However, at the same time, Todd et.al. (2004) emphasize the importance of fostering autonomy when teaching the undergraduate student to do research, especially when doing the final undergraduate project.

Interdisciplinary research provides additional challenges in that it often involves a collaboration between people with different disciplinary specializations and that the interdisciplinary research question is complex in nature. The interdisciplinary research process, as taught at LAS, UU consists of a number of steps, based on the book on interdisciplinary research by Repko and Szostak (2016). Three to four undergraduate students with different disciplinary specializations work together on an interdisciplinary research problem. The research process consists of three different phases. The first phase is to define an interdisciplinary research question. In the second phase all students write their own disciplinary research part where they answer the interdisciplinary research question from a disciplinary perspective. Finally, during the third phase students reflect on the different disciplinary insights and provide an integrated answer to the interdisciplinary research question. As undergraduates have fewer experience with research, they especially can have difficulties with this final phase (Newell, 2006)

Alhough there is many research on blended education, there is not much research on blended support of undergraduate research. There are some examples of research on technological-mediated supervision (Heinze \& Heinze, 2009; Jaldemark \& Lindberg, 2012), but here the focus is more on communication throughout the process instead of providing support during different research phases. In addition, the interdisciplinary research process provides additional challenges to disciplinary undergraduate research. The current paper presents a study of students at the bachelor of LAS, UU, where students learn the interdisciplinary research process in their second year and write an interdisciplinary capstone in their third (final) year of their undergraduate. The study shows results from students on their preferred and current interaction with each other and their supervisor, both online and face-to-face. The paper ends with a discussion, addressing issues that are important when considering the design of a blended framework to support students doing interdisciplinary research. 


\section{Methodology}

This study consisted of two parts. In the first (quantitative) part, a survey was taken of second year students of LAS, who had just completed their first course on interdisciplinary research (Interdisciplinary research I). In addition, the same survey was taken of third year students who had just finished their final interdisciplinary research project (interdisciplinary capstone). In the second (qualitative) part, interviews were held with students who had recently finished their interdisciplinary capstone. In addition, their interdisciplinary supervisors were interviewed.

\subsection{Participants}

All participants were students at the bachelor LAS, UU. For the first part, 22 students of the Interdisciplinary Research I course and 15 students of the Interdisciplinary Capstone took part in the survey. All students were asked to fill in the online questionnaire on the day of their final presentations of their interdisciplinary research projects. The former group had just finished their first interdisciplinary research report. In the latter group, students were doing interdisciplinary research for the second time as all students had finished the Interdisciplinary Research I course at an earlier point in time. Eight students of this group were in their third year of the program and eight students were in their fourth year.

From the students of the capstone that took the survey, two students participated in an interview. These students both had a different interdisciplinary supervisor, who also participated in a separate interview. The supervisors were both junior teachers at the Liberal Arts and Sciences program. Table 1 shows an overview of the students and supervisors who took part in the interviews.

Table 1. Participants in the interviews (anonymized)

\begin{tabular}{cc}
\hline Student & Supervisor \\
\hline Student Sarah & Supervisor Dave \\
Student Eve & Supervisor Fiona \\
\hline
\end{tabular}

\subsection{Survey and interview questions}

Both survey and interview questions were based on literature on dissertation supervision and on elements of the interdisciplinary research process. As the goal of both the survey as well as the interview was also to investigate general supervisor preferences, not all questions were relevant to online or blended supervision. Two questions in the survey were particularly relevant to the topic of blended supervision. One of them was: "how did you work when doing the interdisciplinary integration?" (an important part of doing 
interdisciplinary research). Here, online was an optional answer (amongst other answers such as 'talking to each other', 'on paper' or 'with post-its'). The other question that was asked is "To what extent would you like to use an online tool for...:". Here, six different elements important for the interdisciplinary research process were presented to students (see table 2) and they had to rate on a likert scale (from 1 to 5: totally disagree to totally agree) whether they would like to use an online tool for that element.

Regarding the interview questions, two semi-structured interview schedules were set up to guide the interviews, one for the student interviews and one for the supervisor interviews. The student interview schedule included questions on doing research, on facilitating the interdisciplinary research process and on the preference regarding a specific tool for facilitation of interdisciplinary research. Especially in the second and the third part, questions were relevant for investigating blended supervision, such as: "would you have like to have had more help and if so, during what steps of the interdisciplinary research process?" and "would you like to use and online tool to guide you through the interdisciplinary research process?". For the interview schedule for supervisors, the relevant questions that were included regarding use of an online tool were: "Do you think there could be a different way of supervising?" (indirect), "what part of supervising is done online and what part is done offline?" and "do you see value in an online tool to support students during the interdisciplinary research process"?

Table 2. Possible elements to include in online support of interdisciplinary research

\begin{tabular}{|c|c|}
\hline Progress interdisciplinary process & $\begin{array}{l}\text { As the interdisciplinary research process involves different } \\
\text { steps, it is of use for students to track of where they are in } \\
\text { the process. }\end{array}$ \\
\hline Information different steps & $\begin{array}{l}\text { For each step of the interdisciplinary research process, extra } \\
\text { information could be of relevance to students (such as } \\
\text { theory or examples). }\end{array}$ \\
\hline Communicate between group & $\begin{array}{l}\text { A tool could be used to facilitate communication between } \\
\text { different interdisciplinary research groups. }\end{array}$ \\
\hline Communicate within group & $\begin{array}{l}\text { When doing an interdisciplinary research project, } \\
\text { communication between group members is important. }\end{array}$ \\
\hline To guide the integration & $\begin{array}{l}\text { Integration is an important part of the interdisciplinary } \\
\text { research process and it is not always clear to students what } \\
\text { they should do exactly. }\end{array}$ \\
\hline To visualize the integration & $\begin{array}{l}\text { Visualization of the integration is an important way to show } \\
\text { newly created insights }\end{array}$ \\
\hline
\end{tabular}




\section{Results}

\subsection{Part I: survey on interdisciplinary research supervision}

In this section, results of the survey on interdisciplinary research supervision are presented, including comparisons between the students who had less experience with interdisciplinary research (second year students) and the students who had more experience with interdisciplinary research (capstone students).

Differences were found between the less experienced and the more experienced group on to what extent they would like to use a tool for the different elements involved in doing interdisciplinary research (table 2). The average score of both groups was highest for the element 'information during different steps' and lowest for the element of communication (between and within groups). Figure 1 shows the average scores per elements and the difference between groups. Interestingly, for almost all elements, the less experienced group has a significantly stronger preference towards using a tool as compared to the more experienced group. The exception is communicating between groups, which is relatively low in both groups.

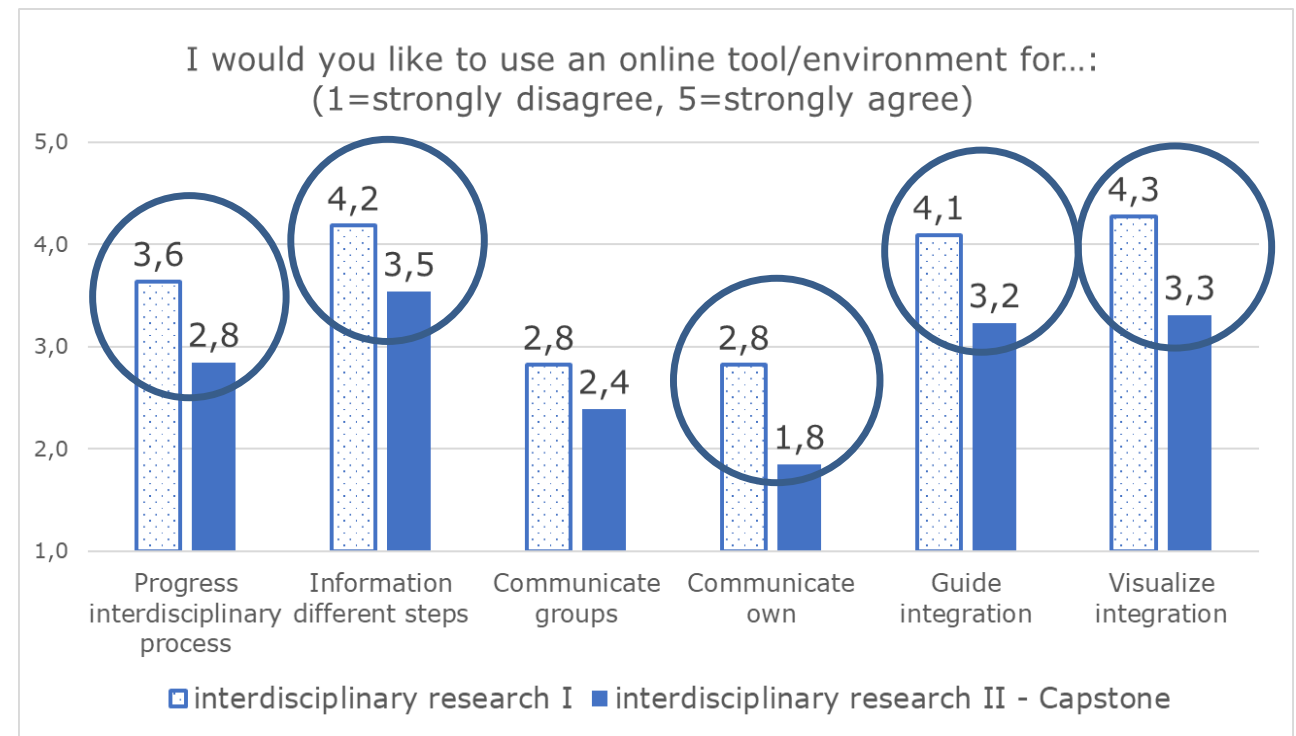

Figure 1. Average scores on tool preference for the less and more experienced group on different elements involved in doing interdisciplinary research. A circle indicates a significant difference $(\mathrm{p}<0.05)$.

When looking at how students worked during the integration of disciplinary insights (multiple answers possible), in both groups the number of students who indicated that they worked on their integration online was lowest (28 percent from the less experienced group indicated and 13 percent of the more experienced group). In addition, the highest 
percentage in both groups was working on the integration by engaging in a conversation with each other (77 percent for the less experienced goup and 86 percent for the more experienced group). This emphasizes the value of meeting face-to-face, but still shows the difference in approach between the less experienced and the more experienced students.

\subsection{Part II: qualitative research}

In this part, results of the qualitative research are presented, consisting of in-depth interviews of two students and their supervisors. As the number of interviews per group (students/supervisors) is limited, results are mainly indicative.

In general, both students and supervisors did have a slight negative attitude towards a new tool to support interdisciplinary learning. Two different topics could be found in the interviews that lay the ground for this negative attitude: the importance of face-to-face interaction and the preference of own tools as opposed to new tools.

\subsubsection{Face-to-face versus digital support}

The importance of face-to-face interaction was stressed several times by the students: Eve mentioned the value of face-to-face interaction nine times and Sarah six times. Especially during the integration phase (phase C), to physically meet and discuss together was found to be essential. On this, Sarah said:

Especially with the integration it is impossible to do that without talking to each other. To share specific disciplinary insights with each other.(...) It is very useful to sit with each other and write down all the insights (Student, Sarah).

In addition, Eve talked about the value of discussing with the supervisor during this phase:

In the feedbacksession with the supervisor, we wrote and drew many of our insights and Fiona gave us suggetions on how to approach that. That was more like collaboaration, like we wrote the dissertation with the four of us, that was really cool. (Student, Eve)

What is apparent is that both supervisors indeed present the integration phase as something they do together with the students. Fiona talks about her experience:

I said: lets put everything we have aside. Then I made a model with them on the whiteboard with the concepts and the relations we were using. (Supervisor, Fiona)

These results could be explained by the creative and meta-cognitive thinking competencies required during the integration phase (Newell, 2006). It involves discussing each other's disciplinary insights and benefits from multiple moments of interaction. However, also other benefits of meeting face-to-face where pointed out, such as meeting other groups to learn about their progress and ask for advice. 


\subsubsection{Use of extisting personal tools}

At multiple occasions in the interview, the students talked about using different online tools, including their personal social media tools, for different purposes. This showed the variety of tools that student are already using on their own account. Eve mentioned using Facebook, Google Docs, email and Whatsapp. Sarah mentioned using Whatsapp, Blackboard and email.

Both students contacted their potential group members online before commencement of the capstone. Eve did this through Facebook and Sarah indicated that she looked at Blackboard for the list of participants and contacted her classmate through Whatsapp. Besides using their personal tools prior to the course, they also indicated using their tools while writing the capstone, mainly for communication and documentation when they were not able to meet each other face-to-face. For example, Eve said:

We were a bit unlucky in that we could not meet with the three of us as often as we would have liked. But in the end it went well, and it was nice that we could make use of Google Docs for that purpose. We hade made a relatively organized drive and Fiona was part of the drive as well. (Student, Eve)

Fiona in this case did not mention the communication through google docs and mentioned mainly communicating through email. Regarding email, both supervisor Fiona and Dave stated that they found communicating through email useful and that they were not particularly enthousiastic to use a new tool. Dave was quite clear that email was the best way to reach him:

Yes, communicating is working well through email. I cannot think of a tool that would be more useful. (Supervisor, Dave).

Also, Fiona specifically mentions the downside of adapting to a new tool when asked about whether giving feedback through an online tool would be useful:

I think not, because you have to learn to work with that as a teacher, and you will learn, but also as a student it is a new environment to deal with. If you do not adapt it in every course (...), then I do not see the benefit over a word-document (Supervisor, Fiona).

\section{Discussion and Conclusion}

Results of this study emphasize the value of providing blended support to students doing undergraduate interdisciplinary research. Especially when students have few experience with interdisciplinary research, they feel an online tool would be useful to get information on during different phases of the process. In addition, they see value in a tool that would support them during the integration phase. This is less so in more experienced students 
when writing their interdisciplinary capstone. However, although students who are writing their interdisciplinary capstone state that they would not be interested in using a new tool for support of their interdisciplinary research, they do mention making use of existing online tools. These tools are often social media tools (Web 2.0 tools) they would use in their social life as well (Whatsapp, Google docs, Facebook). This has benefits as well, considering that Web 2.0 tools have the benefit of encouraging self-regulation (Dabbagh \& Kitsantas, 2012). The value of Web 2.0 tools for technological support is important to keep in mind when designing a blended framework.

This study also emphasizes the importance of face-to-face interaction when supervising interdisciplinary research. This resonates with findings from the literature, where the value of blended learning is that it provides a combination of online and offline support (Ginns \& Ellis, 2007; Heinze \& Heinze, 2009). As the interdisciplinary research process involves collaboration between students with a different disciplinary specializations, meeting faceto-face is even more important. Indeed, students work in different ways to integrate disciplinary insights, such as drawing concepts on the whiteboard and engaging in a discussion with each other and their supervisor. It is therefore important that technologymediated support should complement this experience instead of replacing it, for example by making use of tools that can digitalize visualizations (Davidovitch \& Yavich, 2017).

It should be noted that results from this study are mainly indicative, as the number of students involved is relatively low. In addition, the students interviewed for this study both indicated that they worked relatively well within their group. It is likely that students from groups who have more difficulties have different preferences concerning support of interdisciplinary research. Future work should therefore elaborate on this study to include more students. However, these findings do provide a base to design a blended framework for support of students doing interdisciplinary research. The inclusion of both students and supervisors in the design of such a framework would be essential to create relevant blended support that would help students become independent interdisciplinary researchers.

\section{References}

Dabbagh, N., \& Kitsantas, A. (2012). Personal Learning Environments, social media, and self-regulated learning: A natural formula for connecting formal and informal learning. Internet and Higher Education, 15(1), 3-8. https://doi.org/10.1016/j.iheduc.2011.06.002

Davidovitch, N., \& Yavich, R. (2017). The Effect of Smart Boards on the Cognition and Motivation of Students. Higher Education Studies, 7(1), 60. https://doi.org/10.5539/hes.v7n1p60

Garrison, D. R., \& Kanuka, H. (2004). Blended learning: Uncovering its transformative potential in higher education. Internet and Higher Education, 7(2), 95-105. https://doi.org/10.1016/j.iheduc.2004.02.001 
Ginns, P., \& Ellis, R. (2007). Quality in blended learning: Exploring the relationships between on-line and face-to-face teaching and learning. Internet and Higher Education, 10(1), 53-64. https://doi.org/10.1016/j.iheduc.2006.10.003

Heinze, A., \& Heinze, B. (2009). Blended e-learning skeleton of conversation: Improving formative assessment in undergraduate dissertation supervision. British Journal of Educational Technology, 40(2), 294-305. https://doi.org/10.1111/j.14678535.2008.00923.x

Jaldemark, J., \& Lindberg, O. (2012). Technology-mediated supervision of undergraduate students' dissertations. Studies in Higher Education, 38(9), 1382-1392. https://doi.org/10.1080/03075079.2011.626851

Newell, W. (2006). Decision Making in Interdisciplinary Studies, (January 2007), 245-264. https://doi.org/10.1201/9781420016918.ch13

Repko, A., \& Szostak, R. (2016). Interdisciplinary Research: Process and Theory. Sage.

Shea, P., \& Bidjerano, T. (2010). Learning presence: Towards a theory of self-efficacy, self-regulation, and the development of a communities of inquiry in online and blended learning environments. Computers and Education, 55(4), 1721-1731. https://doi.org/10.1016/j.compedu.2010.07.017 